\title{
Possibilities and problems in using exergy expressions in process integration
}

\author{
Carl-Erik Grip ${ }^{1, *}$, Erik Elfgren ${ }^{1}$, Mats Söderström ${ }^{2}$, Patrik Thollander ${ }^{2}$, Thore Berntsson ${ }^{3}$, \\ Anders Åsblad ${ }^{4}$, Chuan Wang ${ }^{5}$ \\ ${ }^{1}$ LTU (Luleå University of Technology) Division Energy Technology, Luleå, Sweden \\ ${ }^{2}$ LIU (Linköping University), Division Energy Systems, Linköping, Sweden \\ ${ }^{3}$ Chalmers University of Technology, Division Heat and Power Technology, Gothenburg, Sweden \\ ${ }^{4}$ CIT Industriell Energi, Gothenburg, Sweden \\ ${ }^{5}$ Swerea MEFOS, Luleå Sweden \\ *Corresponding author. Tel: +46 9204914 72, Fax: 469204910 74, E-mail: carl-erik.grip@ltu.se
}

\begin{abstract}
Industrial energy systems are complicated networks, where changes in one process influence its neighboring processes. Saving energy in one unit does not necessarily lead to energy savings for the total system. A study has been carried out on the possibility to use the exergy concept in the analysis of industrial energy systems. The exergy concept defines the quality of an amount of energy in relation to its surrounding, expressing the part that could be converted into work. The study consists of literature studies and general evaluations, an extensive case study and an interview study. In the latter it was found that non technical factors are major obstacles to the introduction of exergy.
\end{abstract}

Keywords: Energy efficiency, Exergy, Process integration, User acceptance, Industrial energy system

\section{Introduction}

\subsection{The need and development of process integration in Swedish industry}

Energy use in Swedish industry amounts to more than $40 \%$ of the national energy use. The three most energy-intensive industrial branches in Sweden, pulp and paper, iron and steel and chemical industries use more than two thirds of industrial energy use. Over the years a large effort has been made to increase industrial energy efficiency. This includes measures to increase energy efficiency as well as increased use of excess energy in other branches, e.g. for heat and electricity generation.

One problem is that industrial energy systems are complicated networks where changes in one process, influence its neighboring processes. Thus saving energy in one unit does not necessarily lead to an energy saving for the whole system. A system approach is needed to avoid sub optimization. One early attempt to make a more systematic analysis of this type of problems, the Pinch analysis, was made at Manchester University [1] during the 1970s. A method, pinch analysis, was developed, where the heat-carrying media are categorized as either cold streams (media that are heated during the process) or hot streams (media that are cooled down during the process). They are then added to one hot and one cold stream. The system could be characterized by the point where the composite streams are closest to each other, the pinch point. Exergy analysis [2] and mathematical programming, e.g. the MIND method [3], have been developed for industrial energy system studies starting in the 1980s. A national program to support research, development and use of process integration in Sweden was initiated and financed in cooperation between the Swedish Energy Agency and the Swedish energy-intensive industry [4],[5]. It started 1997 and ended in 2010.

The energy systems of the steel industry are characterized by large high temperature flows of molten solid and gaseous materials, as well as energy intensive chemical reactions. Mathematical programming was considered most suitable for that type of system. A methodology, reMIND, was developed and implemented for practical steel plant use (ref [6]- 
[9]). Based on successful industrial applications three research supporting agencies and a group of Scandinavian steel- and mining companies decided to start and finance an excellence center for process integration in the steel industry, PRISMA which is located at Swerea MEFOS AB in Luleå.

The national program focused on three process integration technologies: Pinch analysis, mathematical programming and exergy analysis. When the work was summarized, it was seen that the main part of research was on mathematical programming and pinch analysis, whereas only a very limited work was made on exergy studies. Considering this, the Process Integration Program of the Swedish Energy Agency has supported a special study on the usefulness of the exergy concept, as well as its limitations and obstacles to future use.

\subsection{What is exergy?}

Energy balances are a common tool in technical energy studies. In these balances energy input equals energy output. This is based on the first law of thermodynamics: energy can neither be destroyed nor be created. The balances also include energy losses. The lost energy has not disappeared; it is converted into a practically useless flow of low-value energy, e.g. used cooling water or waste gas. This indicates the need of a way to describe also the quality of energy flows. The exergy concept defines the quality of an amount of energy in relation to its surrounding, expressing the part that can be converted into work. It is based on the second law of thermodynamics: the entropy of an isolated system never decreases. A certain media can produce work only if there is a difference e.g. in temperature and pressure versus the surrounding. The exergy expression describes the theoretically possible production of work as a function of that difference:

$E=\Delta H-T_{0} * \Delta S$

Where $E=$ exergy, $H=$ enthalpy, $S=$ entropy, $\Delta H$ and $\Delta S$ are differences from the reference state (the surroundings) and $T_{0}=$ the absolute temperature at the reference state.

For a non compressible liquid or solid with constant specific heat the entropy difference can be calculated as

$\Delta S=m * c_{p} * \ln \left(\frac{T}{T_{0}}\right)$

And for an ideal gas as

$$
\Delta S=m *\left(c_{p} * \ln \left(\frac{T}{T_{0}}\right)+R * \ln \left(\frac{p_{0}}{p}\right)\right)
$$

Where $m$ and $c_{p}$ are mass and specific heat, $T$ and $p$ are absolute temperature and pressure of the substance and $T_{0}$ and $p_{0}$ are temperature and pressure at the reference state.

\subsection{Scope of paper}

The main scope is to improve the knowledge of when and how exergy analysis is useful on its own or in combination with other methods and methodologies, as well as on the improvements needed to increase the use of exergy analysis in process integration projects. It was considered important to cover both technical and nontechnical limitations to an improved use. The work was structured in the following parts: literature study, analysis, interview study, case study and synthesis. 


\section{Methodology}

The study was carried out in five steps

Step 1. A literature study with the aim to provide an overview on the utilization and advantages of the exergy analysis method in several systems, especially in industrial ones.

Step 2. An analysis where literature data and experience of the project partners were used to define subsystems where exergy can be used as well as identifying problems and unanswered questions.

Step 3. An interview study with the aim to find the reasons why Exergy was used or not used by different actors. The method was based on a combination of in-depth, semistructured interviews and a more straight-forward questionnaire [10]. Both technical and non-technical aspects were studied. The questions were formulated using the results of the analysis study

Step 4. A case study to demonstrate the practical application on an industrial system. The case chosen was the Luleå Energy: The SSAB steel plant, CHP (combined heat and power plant) and district heating. Collected production data were used for exergy calculations both for the total system and some subsystems

Step 5. A synthesis based on the results from step 1-4 with the aim to answer the following questions: Which criteria for comparison should be used? Should the methodology be used in combination with other methods? Should there be increased dissemination? When should the exergy concept be used? Is exergy research worthwhile? Could the formulation of the exergy concept be explained in a better way? When should the exergy concept and exergy studies be used? Is there a need for exergy research

\section{Results}

\subsection{Literature study}

155 references were included, and 115 of these were described in some detail. The distribution between publication categories is illustrated in Fig. 1 a. The main part of material is distributed almost evenly between journal and conference publications.

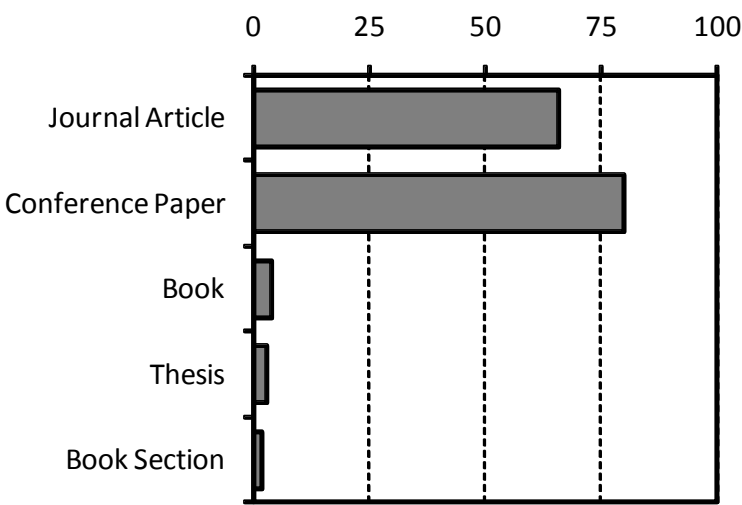

a) Category of publication

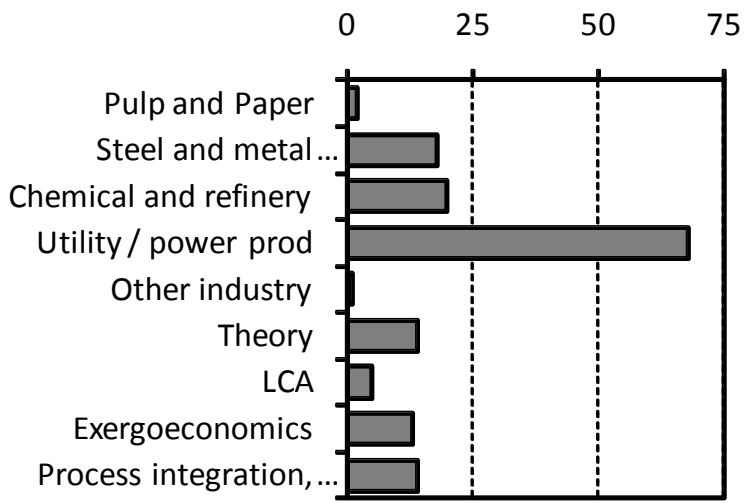

b) Subject of publication

Fig. 1 Distribution of literature references between publication types and subjects. The diagrams show the number of references per category

The collected references described the use in different industrial branches and for specific equipment, some more sophisticated uses, e.g. in LCA or exergoecoonomics, as well as some general studies. The distribution between these subjects is illustrated 
The use is relatively small in the pulp and paper industry. The reason is probably that the transport and exchange of thermal energy is a dominant part of the energy system, which gives a preference for pinch analysis. A higher frequency of references is shown for steel and chemical industry where chemical reactions and energies are important. The power industry and utilities show the highest frequency in Fig. 1 b. A reason can be that components like boilers, turbines, valves and heat exchangers usually entail large exergy destruction rates. The solutions proposed to minimize these losses are often to change operation parameters or to install new equipment with different operating characteristics. The most common action proposed to increase exergy efficiency is to decrease the temperature difference in heat transfer equipment. Since this decreases the driving force, investment costs are likely to increase.

In a system of nodes and streams, exergy analysis is applied to the efficiency of nodes. This can lead to more capital-intensive suggestions e.g. change of process technology.

Several authors suggest using combined pinch and exergy analysis to achieve better results. Pinch analysis could be used to determine minimum cooling and heating demands, thereafter exergy analysis could be used to detect inefficiencies. Finally, the design capabilities of pinch analysis could be used to synthesize a heat exchanger network.

\subsection{Analysis}

The usefulness of the Exergy concept was analyzed separately in pulp and paper, steel industry, mining industry, cement industry, use for electricity generation and for regional cooperation. The result varied between branches. Two interesting uses can be: energy quality to compare subsystems and recovering excess energies. Presently there is a lack of comparison data. Creating a BAT (Best Available Technology) database for energy efficiency and exergy destruction could be interesting. This study also produced parameters for the interview study

\subsection{Interview study}

The aim was to observe the effect of technical and non-technical factors which were of great importance for the introduction of exergy studies as well as for failure or success in the application. The interview form consisted of an interview part where questions were answered in words and a short questionnaire part, where the respondents could rank different obstacles to each other. Fig. 2 illustrates the weighted summary of important obstacles in the questionnaire part. The most important factor seems to be the lack of strategy. Points like lack of time, priorities, lack of capital and slim organization got a low priority. A comment when these points were discussed was: "When we get the job to make an energy analysis the priority is always very high, so those limitations (to the use of exergy analysis, author's remark) are not relevant”. 


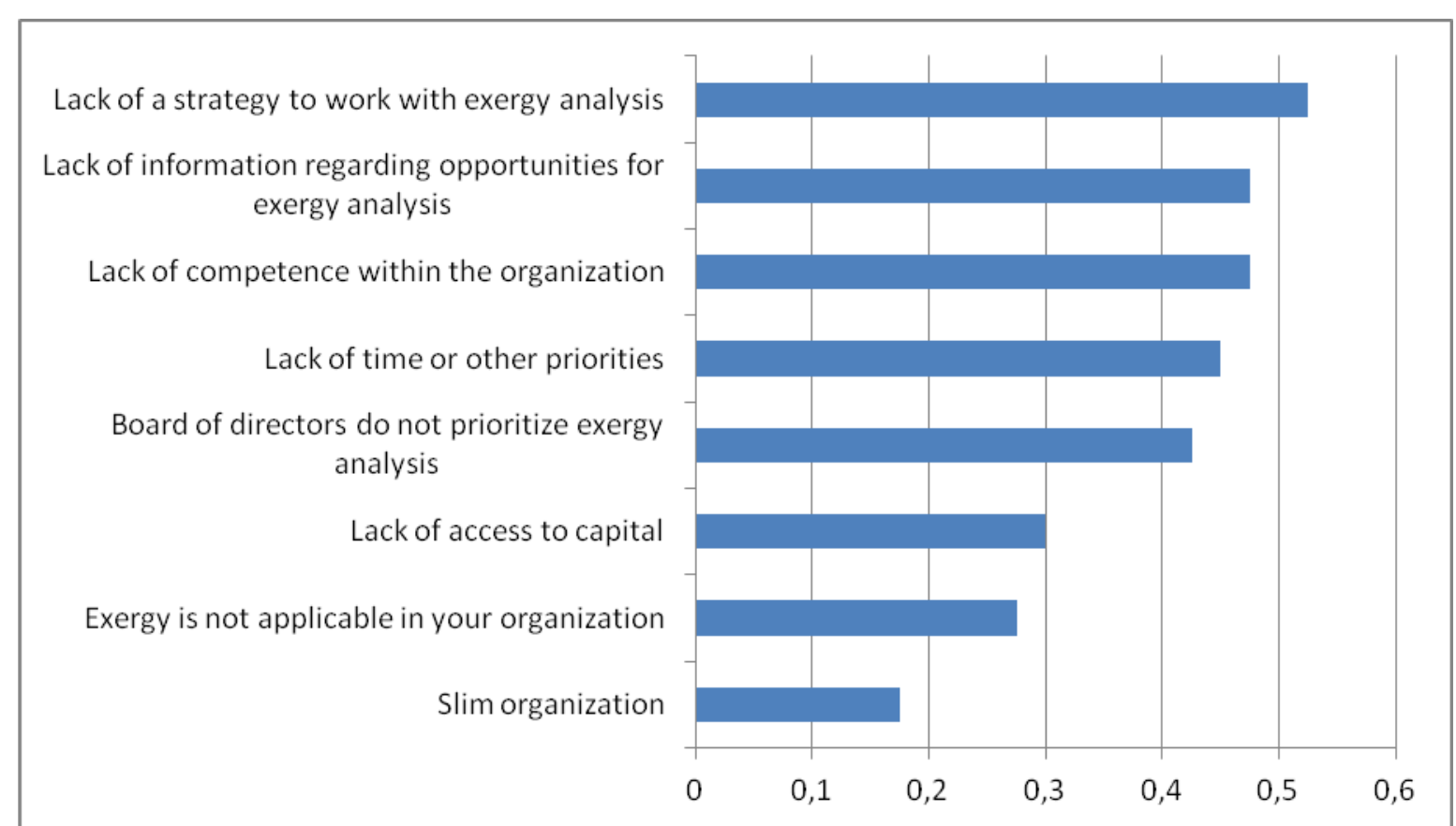

Fig. 2 Weighted summary of obstacles for exergy analysis. Often important $=1$, sometimes important $=0.5$, seldom Important $=0$.

The answers to the in-depth interview questions indicated that one reason for the low rate of applications of exergy analysis is that most missions in the industry, according to respondents, do not require this type of tool, e.g. studies for small and medium-sized businesses. Only about 600 of 59000 manufacturing companies in Sweden are defined as energy-intensive. This can be linked to the obstacles heterogeneity, i.e. the method is not considered by respondents to be applicable in most industries. One reason for the low level of potential applications, however, seems to be that several respondents felt that exergy was difficult to use. One conclusion from this is that the development of software for exergy could promote its use. The major obstacle to exergy analysis that was detected in the interview study was heterogeneity in the technical system level and information imperfections and asymmetries in the socio-technical systems level. (The heterogeneity refers to the fact that different companies have differing conditions for the use of exergy. Imperfections refer to lack of sufficient information and asymmetry to differences in information between different actors.) The highest ranked obstacle to the use of exergy analysis was a lack of strategy. This can be linked to one respondent who indicated that exergy often competes with cost analysis. One conclusion from this is that the tool should be competitive in the analysis of large technical systems where it can be used as decision support for industries or society.

\subsection{Case study}

The case study was made for the Luleå energy system. Existing data for the steel plant site, see ref [11] were extended by data collected from the CHP plant and District heating network.

An example of Sankey diagrams showing energy and exergy flows from the SSAB study 2005 is shown in Fig. 3. In the energy diagram for the blast furnace there is an energy input of $100 \%$, whereas the output is $86.7 \%$ export and $13.3 \%$ losses. The sum of input flows is equal to the sum of the output flows because energy is indestructible according to the first law of thermodynamics. If we instead look at the exergy diagram, both the export and the heat loss flows are lower because the energy consists of energy forms of lower exergy value. Also the 
output exergy is lower than the input exergy. The difference is irreversibly destroyed and corresponds to the entropy increase.

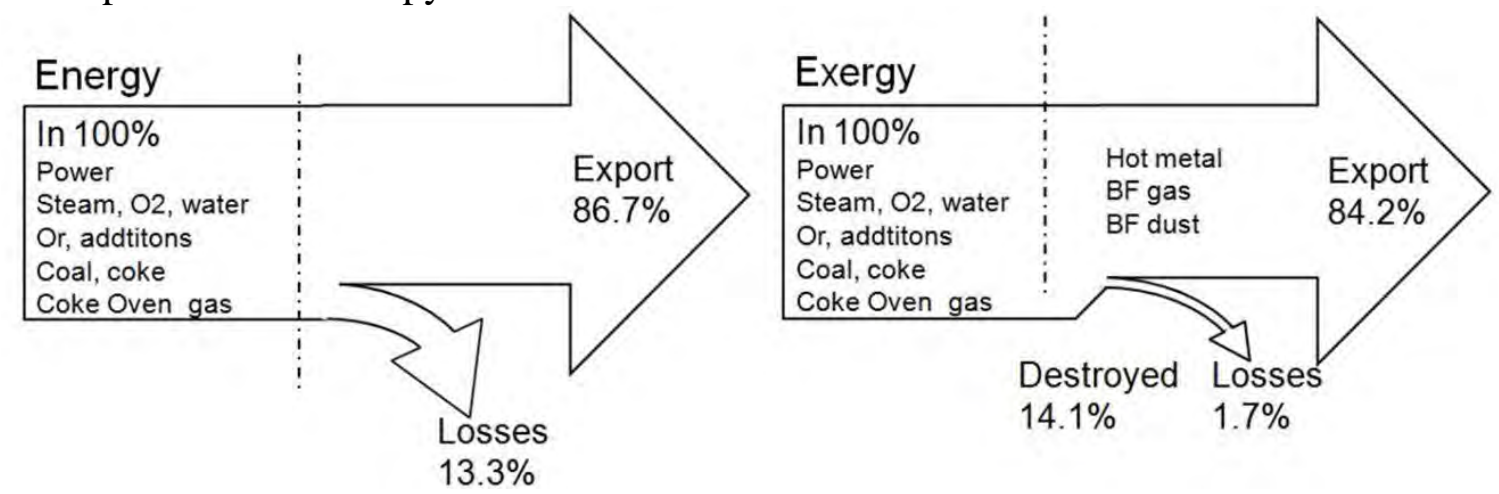

Fig. 3 SSAB Study 2005, Example on Energy-Exergy Diagrams for the blast furnace [12].

The destroyed exergy is a measure of the inefficiency of the unit in question. The heat loss exergy is a measure on the energy that could possibly be recovered.

Fig. 4 shows similar values for the heat and power plant. There are comparatively small heat loss flows, but a relatively high amount of destroyed exergy. The destruction rate is quite different between the units in Fig. 4. It is highest for the boiler and more moderate for the heat exchanger and turbine.

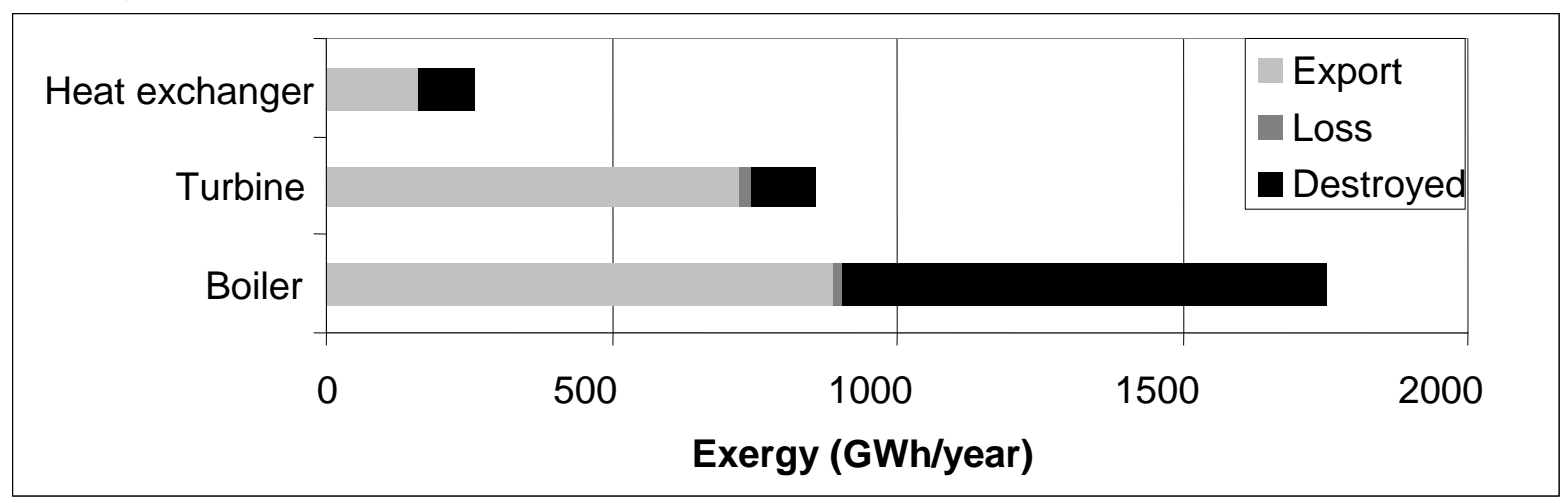

Fig. 4 Example on Exergy balances for the heat and power plant.

The reason for the higher destruction rate in the boiler is that it converts fuel energy (in principle $100 \%$ exergy) into high pressure steam with an exergy content that is roughly $50 \%$ of the enthalpy. It does not indicate a problem with the boiler; the boiler simply has a function where exergy destruction is inevitable. An important conclusion of this is that exergy destruction rate (or exergy efficiency) can be a tool to find out where to look. However, if it is to be used to judge bad or good function a reference value is needed. This could be previous data from the unit or published data. A catalogue for reference exergy data could perhaps be of interest.

Fig. 5 shows a Sankey diagram for the total system: Steel plant - Heat and power plant District heating. The exergy in heat loss flows was relatively small in Fig. 3 but has increased when all steel plant units are increased. This flow represents energy that theoretically could be recovered as higher forms. These results have initiated quantitative studies on recovery e.g. by ORC turbine It can be seen that the exergy is destroyed stepwise through the system. The low amount of exergy in the district heating indicates that a large amount of energy sent to users with a low exergy demand. This can be a potential use for energy recovery from the steel plant. This can be expected to produce media flows with low or moderate exergy content. 


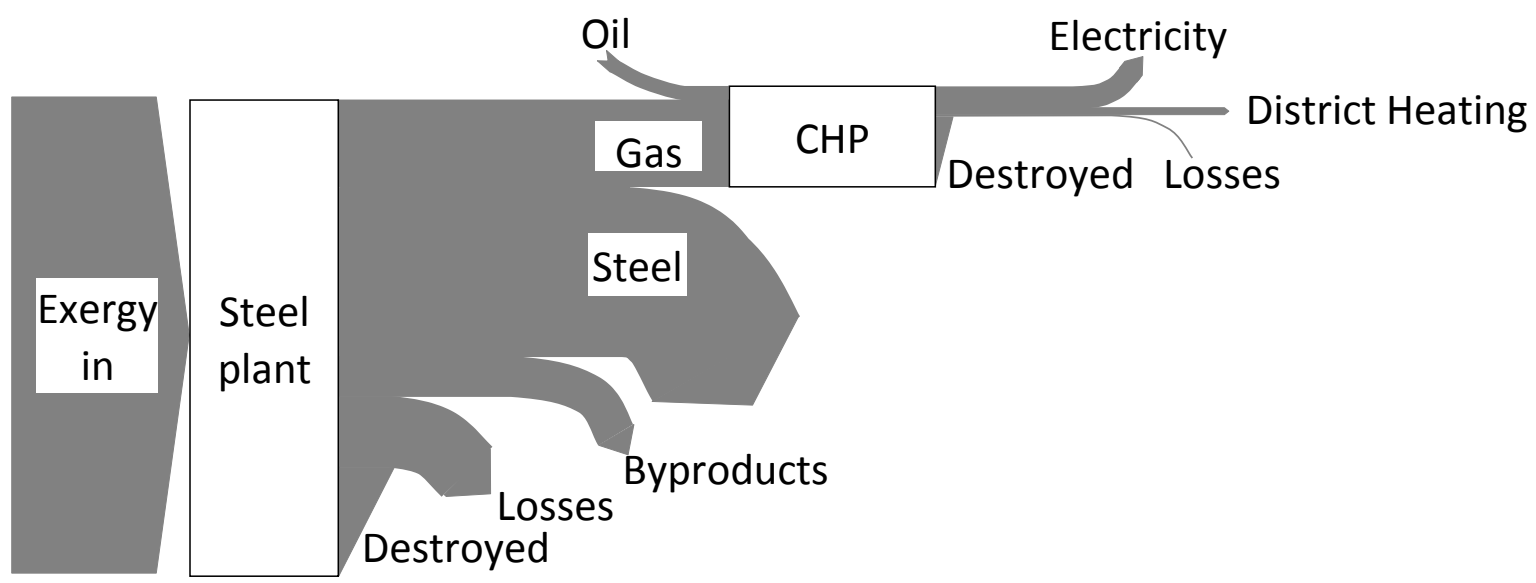

Fig. 5 Exergy flows through the total system

\section{Synthesis, Discussion and Conclusions}

In the project it was shown that:

- Exergy analysis is most competitive for industrial systems dominated by chemical conversions and energies other than thermal energies, e.g. chemical energy. Good examples are the steel industry and the chemical industry, especially refineries. Another important use is systems with different pressures and where production of electricity is of interest.

- Exergy expressions can be used to study process efficiency, possible modifications and mapping possibilities for excess energy recovery.

- Relatively much exergy is used for heating with a low need for exergy, compare Fig. 5. A study to decrease the imbalance using a modified system temperature is planned. Variations in the hot water balance for district heating are also influencing the energy efficiency.

- It is probably better to use a combination of Process integration methods than to only focus on one.

- Inclusion of exergy calculations in the mathematical programming tool reMIND was explored in the case study [15]. Continued work is interesting.

- Non-technical factors are responsible for the slow adoption of exergy analysis, e.g. lack of strategy, heterogeneity, information imperfections and asymmetries.

- The interview study has given an insight into the effect of non-technical parameters. The present technique has a relatively broad spectrum of questions which gives a good result even with a limited amount of respondents.

- Exergy studies are becoming established for system studies in the steel industry. Extension to further sites is being planned.

- A catalogue of reference data would be of interest for better interpretation of results

\section{Acknowledgements}

The authors would like to thank the Swedish Energy Agency for financing the project. We would also like to thank the many interviewees who kindly answered our questions and the people at SSAB, Lulekraft and Luleå Energi who have helped with data collection. 


\section{References}

[1] Linnhoff B. \& Flower J.R., "Synthesis of Heat exchanger Networks I. Systematic generation of energy optimal networks”, Aiche Journal 24 (4), 1978, pp. 633-64

[2] G. Wall, "Exergy Flows in a Pulp and Paper Mill and in a Steel Plant and Rolling Mill", The Fourth International Symposium on Second Law Analysis of Thermal Systems, Rome, 25-29 May, 1987, pp. 131-140, ASME.

[3] Nilsson K. and Söderström M., "Optimising the operation Strategy of a pulp and paper mill using the MIND Method”, Energy, vol. 17 (10), 1992, pp. 945-953

[4] Grip C.-E. and Thorsell A., "Swedish national research program for energy saving by means of process integration", Scanmet II, 2nd International Conference on Process Development in Iron and Steelmaking, June 6-9, 2004, Luleå, Sweden

[5] Grip C.-E., Söderström M., Berntsson T., "Process integration as a general tool for energy intensive process industry. Development and practical applications in Sweden”, SCANMET III (3rd International Conference on Process Development in Iron and Steelmaking), June 8-11, 2008, Luleå, Sweden

[6] Larsson M., Doctoral thesis, Luleå University of Technology, 2004, No.:2004:63, ISSN: $1402-1544$

[7] Larsson M., Sandberg P., Söderström M., Vuorinen H., "System gains from widening the system boundaries: analysis of the material and energy balance during renovation of a coke oven battery”, Int J Energy Res., 2004, pp. 1051-1064

[8] Larsson M., Grip C.-E., Ohlsson H., Rutqvist S., Wikström J.-O., Ångström, S., "Comprehensive study regarding greenhouse gas emission from iron ore based production at the integrated steel plant SSAB TUNNPLAT AB”, International journal of green energy. vol. 3, nr. 2, 2006, pp. 171-183

[9] Wang C., Doctoral thesis, Luleå University of Technology, 2007, No:2007:28, ISSN print):1402-1544

[10]Thollander P., Trygg, L., Svensson, I.-L., ”Analyzing variables for district heating collaborations between energy utilities and industries”, Energy 35 (9), 2010, pp. 36493656

[11]Zetterberg L., "Flows of Energy and Exergy in the Steelmaking process at SSAB Luleå”, Master Thesis SSAB and Chalmers, Gothenburg, 1989

[12]Verbova M., "Energy and Exergy flows in Steelmaking Processes at SSAB Strip Products Division in Luleå”, Master Thesis SSAB and LTU, 2007:080

[13]Grip, C., Dahl, J., Söderström, M., "Exergy as a means for process integration in integrated steel plants and process industry”. Stahl und Eisen, 129, 2009, pp. S2-S8

[14] Malmström, S., "Efficient use of waste energy in the steel industry”, Luleå University of Technology, Master Thesis SSAB and LTU, 2009:110

[15]Elfgren E, Grip C, Wang C and Karlsson J. Possibility to combine exergy with other process integration methods for a steelmaking case. 13th Conference on Process Integration, Modelling and Optimisation for Energy Saving and Pollution Reduction (PRES’10), 28 August - 1 September 2010, Prague, Czech Republic 